\title{
Planejamento tradicional, Location-Based Management System e Last Planner System: um modelo integrado
}

\author{
Traditional planning, Location-Based Management \\ System and Last Planner System: an integrated model
}

\section{Hylton Olivieri \\ Ariovaldo Denis Granja \\ Flávio Augusto Picchi}

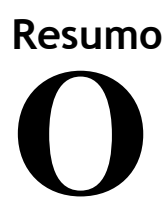

modelo tradicional de planejamento adotado por grande parte das empresas construtoras utiliza como base o método CPM (Critical Path Method). No entanto, devido às limitações deste método, muitas empresas utilizam ferramentas auxiliares para o atendimento das necessidades das equipes de produção, causando dúvidas nas equipes quanto ao trabalho a se realizar, às atividades a serem priorizadas e à melhor utilização dos recursos. $\mathrm{O}$ objetivo desta pesquisa foi elaborar um modelo integrado que preenchesse as lacunas do planejamento tradicional (baseado no método CPM), e que contemplasse elementos dos sistemas de planejamento LBMS (LocationBased Management System) e LPS (Last Planner System). O modelo foi desenvolvido a partir de um estudo de caso exploratório, adotando-se como base o método CPM, incorporado aos conceitos do PMI (Project Management Institute), e os sistemas de planejamento LBMS e LPS. Possui como uma das características a inclusão de processos para integração dos três sistemas nas seguintes fases dos empreendimentos: iniciação, organização e preparação, execução do trabalho e encerramento. $\mathrm{O}$ modelo proposto poderá compensar as limitações de sistemas de planejamento e controle da produção que utilizam ferramentas de maneira fragmentada, uma vez que promove a complementaridade e a sinergia entre eles.

Palavras-chaves: Planejamento tradicional. Planejamento integrado. Location-Based Management System. Last Planner System.

\section{Abstract}

The traditional planning model adopted by most companies is rooted in CPM

Hylton Olivieri Universidade Estadual de Campinas Odebrecht Realizações São Paulo - SP - Brasil

Ariovaldo Denis Granja Universidade Estadual de Campinas Campinas - SP - Brasil

Flávio Augusto Picchi Universidade Estadual de Campinas Lean Institute Brasil São Paulo - SP - Brasil

Recebido em 01/03/15 Aceito em 18/09/15
(Critical Path Method). However, due to the limitations of CPM, several companies use auxiliary tools to address the needs of production teams, leading to uncertainty about the work to be done, activities to be prioritized and uncertainties about the proper use of resources. The aim of this study was to develop an integrated model to fill the gaps of traditional planning (CPM), connecting it to the elements of the planning systems called LBMS (Location-Based Management System) and LPS (Last Planner System). An exploratory case study was carried out to develop the model, which was based on CPM, and the related concepts of PMI (Project Management Institute), and on the planning systems LBMS and LPS. One of its characteristics is the integration of the three planning systems into the following phases: start, planning, execution and closeout. The model could compensate for the limitations of the planning and control systems that use tools in a fragmented way, as it promotes complementarity and synergy between them.

Keywords: Traditional planning. Integrated planning. Location-Based Management System. Last Planner System. 


\section{Introdução}

Modelos tradicionais de planejamento e controle de obras estão fortemente embasados na utilização do método CPM (Critical Path Method) e nos grupos de processos e áreas de conhecimento do PMI (Project Management Institute). Entretanto, esses modelos possuem deficiências e limitações ao atendimento das necessidades das equipes de produção, tais como maior detalhamento do cronograma master e melhor qualidade das informações recebidas (KOSKELA et al., 2002). Outro aspecto importante é a programação formal do tempo. Os cronogramas são elaborados considerando-se todo o prazo de construção, em geral via utilização de técnicas de programação como PERT e CPM, as quais observam principalmente restrições tecnológicas, pouco considerando a existência de interferências entre as tarefas e a incerteza na disponibilização de recursos (LAUFER; TUCKER, 1987).

Diversos trabalhos publicados no International Group of Lean Construction (IGLC) destacam a necessidade de adequação do CPM para a construção, como, por exemplo, em edifícios de múltiplos pavimentos. Os cronogramas não podem ser detalhados com precisão de longo prazo devido à falta de informações sobre durações e pacotes de entrega, além de apresentarem deficiências no gerenciamento diário das atividades (MENDES JUNIOR et al., 1998; TANMAYA et al., 2012; SEPPANEN et al., 2014; KOSKELA et al., 2014).

Um dos problemas de modelos tradicionais de gerenciamento de projetos é o abuso na alocação de folgas de tempo ou buffers nas atividades para proteção do cronograma. Os buffers são adicionados a cada atividade, a fim de acomodar potenciais incertezas, causando o efeito de que as atividades sucessoras não são realizadas porque não está claro quando a atividade predecessora será concluída. Como resultado as atividades não estão prontas para iniciar-se quando as atividades predecessoras são concluídas (KOSKELA et al., 2014). Os modelos tradicionais assumem que a variação no fluxo de trabalho foge ao controle do gerenciamento. Contingências de várias formas são utilizadas na tentativa de acomodar ou absorver essa variação externa dentro dos limites de prazo e custo do empreendimento (BALLARD; HOWELL, 2004).

As temáticas CPM, LPS (Last Planner System), LBMS (Location-Based Management System) e suas ferramentas também têm recebido atenção da comunidade científica nacional (entre outros, Assumpção e Fugazza (1998), Bortolazza e Formoso (2006), Kemmer et al. (2008), Viana et al. (2010), Bulhões e Picchi (2013) e Viana et al.
(2013). Via de regra, essas pesquisas têm seus focos direcionados à compreensão e implantação dessas técnicas e ferramentas de maneira individualizada. Ainda que alguns trabalhos tenham proposto a síntese e a integração de sistemas de planejamento e de gestão da produção (KOSKELA et al., 2010; CARDIM; GRANJA, 2011), as técnicas de redes tais como o CPM continuam entre os procedimentos mais utilizados, principalmente em função da disseminação de pacotes computacionais para planejamento e controle de empreendimentos (ASSUMPÇÃO, 1996).

Sob um enfoque crítico, o LPS é um sistema que apresenta dificuldades na medição do desempenho de um empreendimento a partir da execução de atividades no curto prazo (HUBER; REISER, 2003). Por outro lado, este é justamente um dos pontos positivos do modelo tradicional. O LPS também apresenta a vantagem de lidar com as incertezas características de empreendimentos da construção civil (HAMZEH et al., 2012), ponto este falho no modelo tradicional. Por fim, o LBMS confere mais transparência ao processo de planejamento e controle da produção ao contemplar aspectos importantes como o fluxo de trabalho e restrições de locais (KENLEY; SEPPANEN, 2010; BUCHMANN-SLORUP, 2012). Portanto, há justificativa e oportunidade de preenchimento de lacuna de conhecimento na busca de integração e de sinergia entre os métodos tradicionais de planejamento e as técnicas e ferramentas do LPS e LBMS.

O objetivo desta pesquisa foi elaborar um modelo integrado que preenchesse lacunas do planejamento tradicional (baseado no método CPM) e que contemplasse elementos dos sistemas de planejamento denominados LBMS e LPS. A premissa inicial não foi abolir a utilização do método CPM, visto que ele ainda é utilizado em larga escala em empresas do setor, mas sim admitir que este possui limitações e que necessita de sistemas complementares para o atendimento das necessidades das equipes gerenciais e de produção. Pressupondo a complementaridade e a sinergia entre os três sistemas, o artigo tem como foco conceitual propor a integração de ferramentas de planejamento e controle da produção.

\section{Sistemas de planejamento}

O sistema de planejamento de obras é basicamente dividido em duas metodologias principais:

(a) Activity-Based (AB); e 


\section{(b) Location-Based (LB).}

As duas metodologias possuem vários métodos e técnicas, porém são principalmente associadas com dois métodos de planejamento principais: CPM (AB) e Linha de Balanço (LB). Mais amplo do que isso, a metodologia $\mathrm{AB}$ também é conhecida pela utilização das ferramentas PERT e cronogramas de Gantt (ou cronogramas de barras), enquanto a metodologia LB pode ser conhecida como harmonogramas, tempo-caminho, tempo-espaço ou linha de fluxo (KENLEY, 2004; JONGELING; OLOFSSON, 2007; KENLEY; SEPPANEN, 2010; BUCHMANN-SLORUP, 2012). Dos três sistemas de planejamento abordados neste trabalho, dois fazem parte da metodologia $\mathrm{AB}$ (planejamento tradicional e LPS) e um da metodologia LB (LBMS).

A metodologia $\mathrm{AB}$ é atualmente a técnica predominante nas construções. Essa técnica foi inicialmente desenvolvida na década de 1950, pela empresa du Pont de Nemours \& Co., a partir da formação de um grupo integrado de engenharia. Esse grupo desenvolveu em 1957 uma nova técnica, chamada de método Kelley-Walker, gerando o primeiro software comercial, denominado Ramps (Resource Analysis and MultiProject Scheduling) (KENLEY; SEPPANEN, 2010). O PMI desenvolveu conceitos e boas práticas que utilizam como base a metodologia AB. Fundado em 1979, o PMI é uma instituição sem fins lucrativos que divulga boas práticas no gerenciamento de projetos (obras) por intermédio de padrões, guias e programas de certificações, sendo seus conceitos aplicados no gerenciamento de projetos.

A metodologia LB é ainda mais antiga que a metodologia AB. Kenley e Seppanen (2010) acreditam que o professor polonês Karol Adamiecki desenvolveu no início do século XX as bases do planejamento com base em locais. Originalmente baseada em técnicas gráficas e utilizada em 1929 em projetos inovadores como o Empire State Building, foi desenvolvida pela Goodyear na década de 1940, expandida na década de 1950 pela US Navy e objeto de várias pesquisas nas décadas de 1960 e 1970 (KENLEY; SEPPANEN, 2010; TANMAYA et al., 2012).

A metodologia $\mathrm{AB}$ tem como foco principal o desenvolvimento de cronogramas que gerem uma análise de caminho crítico do empreendimento, enquanto a metodologia LB possui foco mais direcionado à produção das obras, analisando-se as folgas, os recursos disponíveis e os locais das atividades. A literatura que aborda a aplicação integrada e simultânea das duas metodologias é bastante escassa, havendo uma lacuna de conhecimento acerca dessa abordagem e dos benefícios que podem ser gerados.

\section{Planejamento tradicional}

Tradicionalmente, mais de $90 \%$ das empresas de construção civil nos Estados Unidos utilizam o método CPM para gerenciar seus projetos (LOWE et al., 2012). O CPM é utilizado primeiramente para otimização das durações, em vez de lidar com as restrições dos recursos, a fim de garantir uma suave passagem das equipes de unidade para unidade, com o mínimo de conflitos e tempo inativo para as equipes e equipamentos (LOWE et al., 2012). O método CPM tem sido aclamado como a mais importante inovação no gerenciamento de construções no século XX. Apesar de amplamente criticado como inadequado para o controle do trabalho em projetos, o método é amplamente utilizado e ensinado (KOSKELA et al., 2014)

Os processos de gerenciamento de projetos são aplicados globalmente nos mais variados setores econômicos e industriais, em diversos países. O modelo desenvolvido pelo PMI conceitua o gerenciamento de projetos como a aplicação do conhecimento, habilidades, ferramentas e técnicas às atividades do projeto para atender a seus requisitos (PROJECT..., 2013). De todos os grupos de processos e áreas do conhecimento considerados pelo PMI, neste trabalho são levados em conta apenas os grupos de processo de planejamento, monitoramento e controle, e as áreas do conhecimento denominadas escopo, tempo e custos, pois estes possuem correlação direta com o planejamento e controle físico das obras.

No planejamento tradicional o trabalho é tratado como uma série de pacotes que possuem uma relação baseada no tempo com outros pacotes. Cada pacote de trabalho é considerado distinto, e o método não explicita claramente onde é a alocação física e o relacionamento desse pacote com os demais locais, ou seja, não há uma relação baseada em locais entre as atividades (KENLEY; SEPPANEN, 2010).

\section{Location-Based Management System (LBMS)}

O sistema LBMS é o produto de um processo de pesquisa iniciado com a linha de balanço e o método de fluxo de trabalho. A descrição completa do sistema LBMS, com sua história e desenvolvimento, pode ser encontrada no trabalho de Kenley e Seppanen (2010). De uma forma geral, o sistema LBMS está inserido no método $\mathrm{LB}$, sendo que o sistema LBMS possui um foco 
mais amplo e direcionado ao processo de controle, enquanto o LB foca principalmente no processo de planejamento.

O LBMS é uma técnica de planejamento e controle da produção em construções, adicionando aspectos importantes no processo de construção que podem ser omissos em outras técnicas, como o fluxo de trabalho contínuo e as restrições de locais. O LBMS combina taxas de produção, quantidades e consumo de recursos em locais específicos para estimar as durações das atividades (BUCHMANNSLORUP, 2012). Frequentemente visualizado como linha de fluxo, em que as quantidades de projeto, dados de produtividade e locais formam o cálculo que define as durações e recursos requeridos para as tarefas alocadas (TANMAYA et al., 2012), o sistema LBMS adiciona linhas de fluxo aos cronogramas de Gantt, melhorando a visualização dos cronogramas. A Figura 1 mostra um exemplo de cronograma LBMS para as atividades de vedações, comparando as datas previstas, realizadas e projetadas para cada atividade e local, e apontando alarmes para os principais desvios detectados.

A principal contribuição do LBMS é a utilização da Estrutura de Locais do Projeto (ELP), combinando os algoritmos CPM com as técnicas baseadas em locais por meio de rede lógica, além do controle de quantidades por unidade de locais (SEPPANEN et al., 2014). Um planejamento linear, repetitivo e baseado em locais pode modelar o fluxo de trabalho e conectá-lo diretamente com os critérios de medição das unidades de produção e locais. Esse modelo de fluxo de trabalho é orientado para mostrar as interações do processo de construção dentro da perspectiva de tempo e locais (LUCKO et al., 2013).

\section{Last Planner System (LPS)}

O Last Planner System (LPS) é um sistema de planejamento e controle que nasceu da visão do planejamento baseado em atividades. O LPS é um processo social que envolve discussão com as equipes de obra e planejamento no intuito de assegurar que o trabalho não está esperando pelos trabalhadores e que os trabalhadores não estejam esperando pelo trabalho (KENLEY; SEPPANEN, 2010). Para Ballard (2000) o LPS pode ser entendido como um mecanismo para transformar o que poderia ser feito no que pode ser feito, utilizando o plano de trabalho semanal.

Figura 1 - Modelo de cronograma LBMS

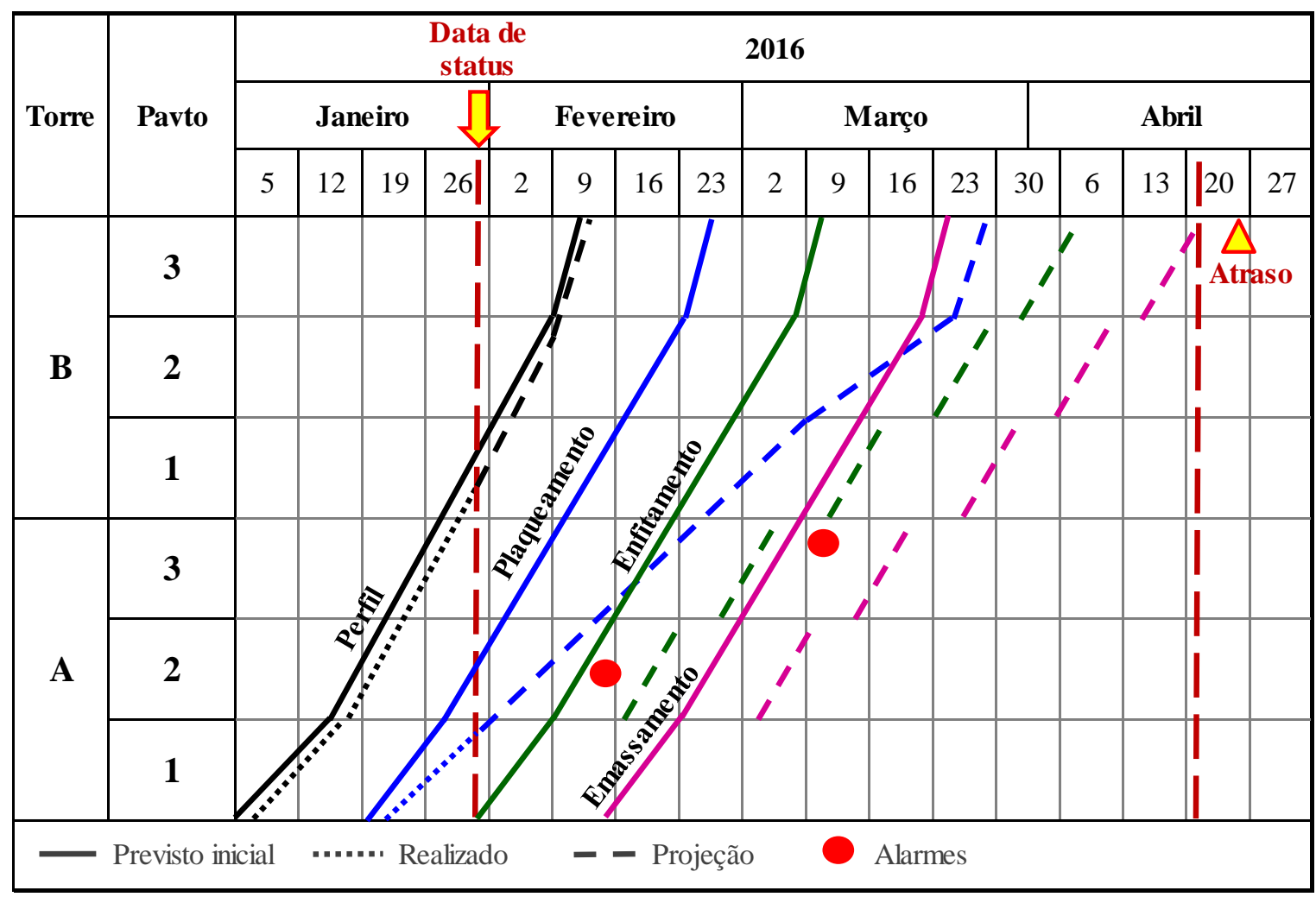

Fonte: adaptado de Lowe et al. (2012). 
O método LPS possui cinco elementos principais integrados:

(a) planejamento master;

(b) planejamento faseado (divisão do planejamento master em fases, fazendo o "elo" entre a planejamento master e o planejamento de médio prazo);

(c) planejamento de médio prazo;

(d) planejamento de curto prazo; e

(e) porcentual de pacotes completos e análise das razões das tarefas não completadas.

No dizer dos autores, quando sistematicamente implantados na prática, esses cinco elementos podem trazer vantagens e benefícios no planejamento das construções (BALLARD, 2000; KOSKELA et al., 2010).

O LPS assume que as atividades planejadas contêm incertezas e restrições que as inibem de ser iniciadas ou completadas no prazo. Incertezas e restrições em atividades planejadas incluem a disponibilidade oportuna de recursos e requisitos prévios ao trabalho. As incertezas e restrições são reveladas e endereçadas ao processo de planejamento de médio prazo (KIM; BALLARD, 2010).

\section{Método de pesquisa}

A estratégia de pesquisa adotada para o desenvolvimento do modelo integrado foi o estudo de caso exploratório, seguido pelo desenvolvimento do modelo integrado e por uma avaliação-piloto desse modelo por meio de entrevistas estruturadas com profissionais de construção civil que atuam nas áreas de gerenciamento, planejamento ou produção. Como limitação desta pesquisa, aponta-se que um dos autores deste trabalho possuiu vínculos profissionais com as duas empresas, o que pode resultar em possível viés.

O estudo de caso é uma investigação empírica que observa um fenômeno contemporâneo em profundidade e em seu contexto de vida real, especialmente quando os limites entre o fenômeno e o contexto não são claramente evidentes (YIN, 2010). Uma contribuição teórica é fundamentada pela resposta às questões "o quê", "como", "por quê" e "quem, onde e quando". "O quê" considera os fatores que explicam o fenômeno de interesse. "Como" visa conectar e ordenar os fatores. "Por quê" é a justificativa para a escolha do tema, e "quem, onde e quando" relacionam as limitações da teoria proposta (WHETTEN, 1989). O Quadro 1 aborda as contribuições do artigo no desenvolvimento da teoria de integração.

$\mathrm{O}$ estudo de caso exploratório foi realizado em duas incorporadoras atuantes no mercado imobiliário brasileiro. As empresas estão listadas entre as 40 maiores empresas de construção no Brasil no ano de 2012, segundo ranking da revista O Empreiteiro (2012). Atuam principalmente nas classes sociais A, B e C, com foco em obras para fins residenciais, corporativos e uso misto. Para fins deste trabalho, as empresas não terão sua identidade revelada, sendo denominadas apenas como Empresa A e Empresa B.

\section{Quadro 1 - Desenvolvimento de teoria de integração}

\begin{tabular}{|l|l|}
\hline O quê & $\begin{array}{l}\text { Modelo de integração do planejamento tradicional com os sistemas de planejamento } \\
\text { LBMS e LPS, com a identificação dos principais processos nas fases iniciação, } \\
\text { organização e preparação, execução do trabalho encerramento. }\end{array}$ \\
\hline Como & $\begin{array}{l}\text { A partir do estudo de caso exploratório realizado em duas empresas, os processos } \\
\text { foram identificados, ordenados e classificados seguindo dois fatores: (a) planejamento } \\
\text { tradicional, LBMS e/ou LPS e (b) itens com características voltadas a tempo, } \\
\text { atividade ou local. Após o desenvolvimento do modelo integrado, realizou-se uma } \\
\text { avaliação-piloto do modelo com profissionais atuantes no setor de construção civil. }\end{array}$ \\
\hline Por quê & $\begin{array}{l}\text { O intuito é melhorar o que já existe no modelo tradicional, que utiliza como base o } \\
\text { método CPM, suprindo as deficiências deste método por meio da sinergia e da } \\
\text { incorporação dos sistemas de planejamento LBMS e LPS. }\end{array}$ \\
\hline $\begin{array}{l}\text { Quem, onde e } \\
\text { quando }\end{array}$ & $\begin{array}{l}\text { O modelo proposto está em fase de desenvolvimento e ainda não foi aplicado ou } \\
\text { avaliado em sua totalidade. }\end{array}$ \\
\hline
\end{tabular}

Fonte: adaptado de Whetten (1989). 
A Empresa A atua no mercado há 35 anos e possui cerca de 3.000 integrantes. A Empresa B possui 8 anos de existência e conta com cerca de 8.600 integrantes. As duas empresas possuem forte tradição na utilização dos conceitos de gerenciamento de projetos, utilizando em seus empreendimentos de forma parcial técnicas e ferramentas do planejamento tradicional e dos sistemas LBMS e LPS.

A Empresa A possui uma gestão matricial, em que seus empreendimentos aplicam os mesmos processos, procedimentos e ferramentas. O trabalho de desenvolvimento e atualização das ferramentas de planejamento é feito por equipes próprias. A Empresa $\mathrm{B}$ possui uma gestão descentralizada por projetos, em que cada empreendimento possui autonomia para definir processos, procedimentos e ferramentas que mais se adequam ao perfil de seus gestores. Nesta empresa, o trabalho de desenvolvimento e atualização das ferramentas de planejamento é feito usualmente por empresas terceirizadas. As principais evidências levantadas nas duas empresas foram os procedimentos, documentos, planilhas e ferramentas utilizados em empreendimentos reais, já finalizados ou em andamento.

A unidade de análise nas duas incorporadoras foi o sistema de planejamento, monitoramento e controle, incluindo ferramentas e técnicas utilizadas na gestão da produção. No caso da Empresa A, a unidade de análise é padronizada e utilizada nos empreendimentos. No caso da Empresa B, ela é descentralizada, e as evidências foram coletadas em dois empreendimentos, localizados na cidade de São Paulo, que utilizam os mesmos processos e procedimentos. De maneira geral, a coleta de evidências se deu por meio de análise documental, por meio de documentos eletrônicos. O processo de coleta levou cerca de 90 dias e contou com visitas de um dos autores deste trabalho às obras da Empresa $\mathrm{B}$, além da análise dos arquivos de dez obras da Empresa A. Todos os documentos de análise foram disponibilizados pelas empresas, sendo no total analisados cerca de 100 arquivos.

A partir da análise dos procedimentos de planejamento e controle de obras adotados pelas empresas, foram acessados os seguintes documentos:

(a) cronogramas físicos (CPM);

(b) curvas físicas (ou curvas de agregação de recursos (HEINECK, 1990);

(c) linhas de balanço;

(d) planilha de metas mensais; (e) cronogramas de suprimentos;

(f) planejamento de médio prazo (análise de restrições);

(g) planejamento de curto prazo (planejamento operacional);

(h) definições de planos de EAP (Estrutura Analítica do Projeto) e critérios de medições; e

(i) relatório de status (mostra o estágio atual dos empreendimentos).

Os documentos foram analisados levantando-se as características, qualidades e deficiências em cada um deles no que diz respeito a um processo de planejamento integrado.

A partir do estudo de caso exploratório e da revisão bibliográfica do planejamento tradicional e dos sistemas LBMS e LPS, os autores propuseram um modelo que integra de forma horizontal (entre fases distintas da obra) e vertical (dentro de uma mesma fase) os principais processos nos três sistemas. A partir de uma classificação por fases e a fim de exemplificar o modelo, cada ligação entre processos é descrita, sendo em alguns casos exemplificadas ferramentas que podem ser utilizadas. As ferramentas ilustradas não fazem referência a um empreendimento específico, porém foram utilizadas pelas empresas analisadas no estudo de caso exploratório. Por fim, o modelo foi avaliado por gestores.

As entrevistas estruturadas são elaboradas mediante questionário totalmente estruturado, ou seja, é aquela em que as perguntas são previamente formuladas e tem-se o cuidado de não se fugir a elas. O principal motivo desse zelo é a possibilidade de comparação com o mesmo conjunto de perguntas e que as diferenças devem refletir diferenças entre os respondentes, e não diferença nas perguntas (LAKATOS; MARCONI, 1996). Os questionários podem ser enviados aos informantes de forma eletrônica ou impressa. Quando isso acontece, deve-se enviar uma nota explicando a natureza da pesquisa.

Para a avaliação-piloto foram elaboradas 17 questões de múltipla escolha, fazendo-se uso da ferramenta Google Docs. No início dos formulários foi inserida uma breve descrição sobre o objetivo da entrevista, o que seria o modelo integrado e as principais características dos sistemas de planejamento abordados na integração. As entrevistas foram enviadas via correio eletrônico para 49 profissionais das áreas de gerenciamento, planejamento e produção, que atuam em quatro empresas de grande porte presentes no ranking da revista $\mathrm{O}$ Empreiteiro (2012). Desse montante, 39 profissionais 
responderam ao questionário. $\mathrm{O}$ processo de elaboração da entrevista, coleta de informações e análise dos resultados levou cerca de 20 dias para ser realizado. O Quadro 2 detalha as características das empresas participantes da entrevista.

\section{Resultados}

O Quadro 3 ilustra os principais processos e ferramentas utilizados pelas empresas do estudo de caso, levando em consideração as quatro fases do ciclo de vida dos empreendimentos: iniciação, organização e preparação, execução do trabalho e encerramento. As duas empresas utilizam como base o cronograma CPM, porém, devido às limitações que o método CPM apresenta com relação ao atendimento às equipes de produção (maior nível de detalhamento das atividades e mais facilidade visual), as empresas adotam como ferramenta auxiliar o sistema LPS durante a fase de execução do empreendimento. Além do LPS, a Empresa B adota também uma linha de balanço durante as fases de organização, preparação e execução do trabalho.

Nas duas empresas o cronograma CPM é desenvolvido no software MS Project e possui como data de término a data contratual estabelecida com os clientes. Analisando esse processo sob a ótica do sistema LBMS, notamos que é dedicada pouca atenção a itens como:
(a) locais;
(b) análise de equipes;
(c) análise de recursos;
(d) adição de folgas; e
(e) quebra de continuidade de atividades, sendo estes relacionados às equipes de produção.

O cronograma CPM é estruturado de acordo com a EAP (Estrutura Analítica do Projeto) do empreendimento, o que facilita sua análise e elaboração. Além de organizar as atividades do empreendimento, a EAP apresenta ainda as divisões e definições dos critérios de medição estabelecidos. Para o desenvolvimento do cronograma CPM, as empresas adotam modelos de sequenciamento padrão para as atividades. O modelo adotado pela Empresa A está ilustrado na Figura 2. Outra ferramenta bastante utilizada é o plano de ataque, que define a sequência de início e de interferência entre os principais serviços do empreendimento.

Quadro 2 - Empresas participantes da avaliação-piloto

\begin{tabular}{|l|c|c|c|c|}
\hline Enpresa & $\begin{array}{c}\text { Tempo de } \\
\text { atuação no } \\
\text { mercado (anos) }\end{array}$ & Classificação da empresa & Região de atuação & $\begin{array}{c}\text { Colaboradores } \\
\text { que participaram } \\
\text { da avaliação-piloto }\end{array}$ \\
\hline Empresa 1 & 8 & Incorporadora e construtora & Nacional & 23 \\
\hline Empresa 2 & 35 & Incorporadora e construtora & Nacional & 12 \\
\hline Empresa 3 & 45 & Incorporadora e construtora & Estado de São Paulo & 2 \\
\hline Empresa 4 & 45 & Construtora & Estado de São Paulo & 2 \\
\hline
\end{tabular}

Quadro 3 - Comparativo entre empresas

\begin{tabular}{|c|c|c|c|c|}
\hline \multirow{2}{*}{ 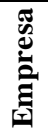 } & \multicolumn{4}{|c|}{ Fases do Empreendimento } \\
\hline & Iniciação & Organização e preparação & Execução do trabalho & Encerramento \\
\hline $\mathbf{A}$ & $\begin{array}{l}\text { Cronograma } \\
\text { para } \\
\text { definição de } \\
\text { prazos e } \\
\text { etapas }\end{array}$ & $\begin{array}{l}\text { Plano de Ataque } \\
\text { Cronograma CPM } \\
\text { Curva física } \\
\text { Cronograma de Suprimentos }\end{array}$ & $\begin{array}{l}\text { Atualização do cronograma CPM } \\
\text { Planilhas de meta de produção } \\
\text { Planejamento de médio prazo } \\
\text { Planejamento de curto prazo }\end{array}$ & - \\
\hline B & $\begin{array}{l}\text { Cronograma } \\
\text { para } \\
\text { definição de } \\
\text { prazos e } \\
\text { etapas }\end{array}$ & $\begin{array}{l}\text { Plano de Ataque } \\
\text { Cronograma CPM } \\
\text { Curva física } \\
\text { Cronograma de Suprimentos } \\
\text { Linha de balanço }\end{array}$ & $\begin{array}{l}\text { Atualização dos cronogramas CPM e LBMS } \\
\text { Planejamento de médio prazo } \\
\text { Planejamento de curto prazo } \\
\text { Relatório de Status }\end{array}$ & $\begin{array}{l}\text { Lições } \\
\text { aprendidas }\end{array}$ \\
\hline
\end{tabular}


Além disso, neste cronograma são inseridos os custos orçados para cada atividade, gerando assim informações suficientes para o desenvolvimento da curva física dos empreendimentos. A partir das datas do cronograma CPM e das definições dos prazos de contratações, tempo de mobilização de fornecedores de mão de obra e tempo de entrega de materiais, é definido também um cronograma de suprimentos.

Como a Empresa B adota os cronogramas CPM e linha de balanço, nas fases de organização, preparação e execução do trabalho são desenvolvidos e atualizados mensalmente dois cronogramas num mesmo empreendimento. No caso da Empresa B, é a linha de balanço que gera as informações para o planejamento de médio e curto prazo voltados às equipes de produção. Já a Empresa A utiliza como elo entre o cronograma CPM e as equipes de produção uma planilha denominada Metas de Produção. Nela, além das atividades a se realizar no período, são informadas as participações percentuais nos orçamentos de cada atividade e se a atividade faz parte do caminho crítico da obra.
Com referência às ferramentas do sistema LPS, as duas empresas utilizam os mesmos modelos, ou seja, planilhas para a identificação, acompanhamento e remoção de restrições e para o planejamento semanal das atividades. Na Empresa A as reuniões de remoção de restrições ocorrem mensalmente, com uma grande preocupação na identificação correta das restrições. As reuniões com as equipes de produção são semanais e registradas em planilhas. Nestas reuniões as metas são informadas e discutidas, além de monitorados e apresentados os resultados de porcentual de pacotes concluídos (PPC) de períodos anteriores. $\mathrm{Na}$ Empresa $\mathrm{B}$ as reuniões de remoção de restrições não são realizadas de forma estruturada e não há a obrigatoriedade da realização de forma periódica. Quando ocorrem, as identificações das restrições são mais superficiais se comparadas à outra empresa. O planejamento semanal das atividades é realizado pela equipe de produção, sem a participação da equipe de planejamento, e as informações são registradas em atas de reunião. Muitas vezes os índices de PPC não são registrados, nem informados aos empreiteiros.

Figura 2 - Modelo de sequenciamento padrão (conjunto parcial de atividades)

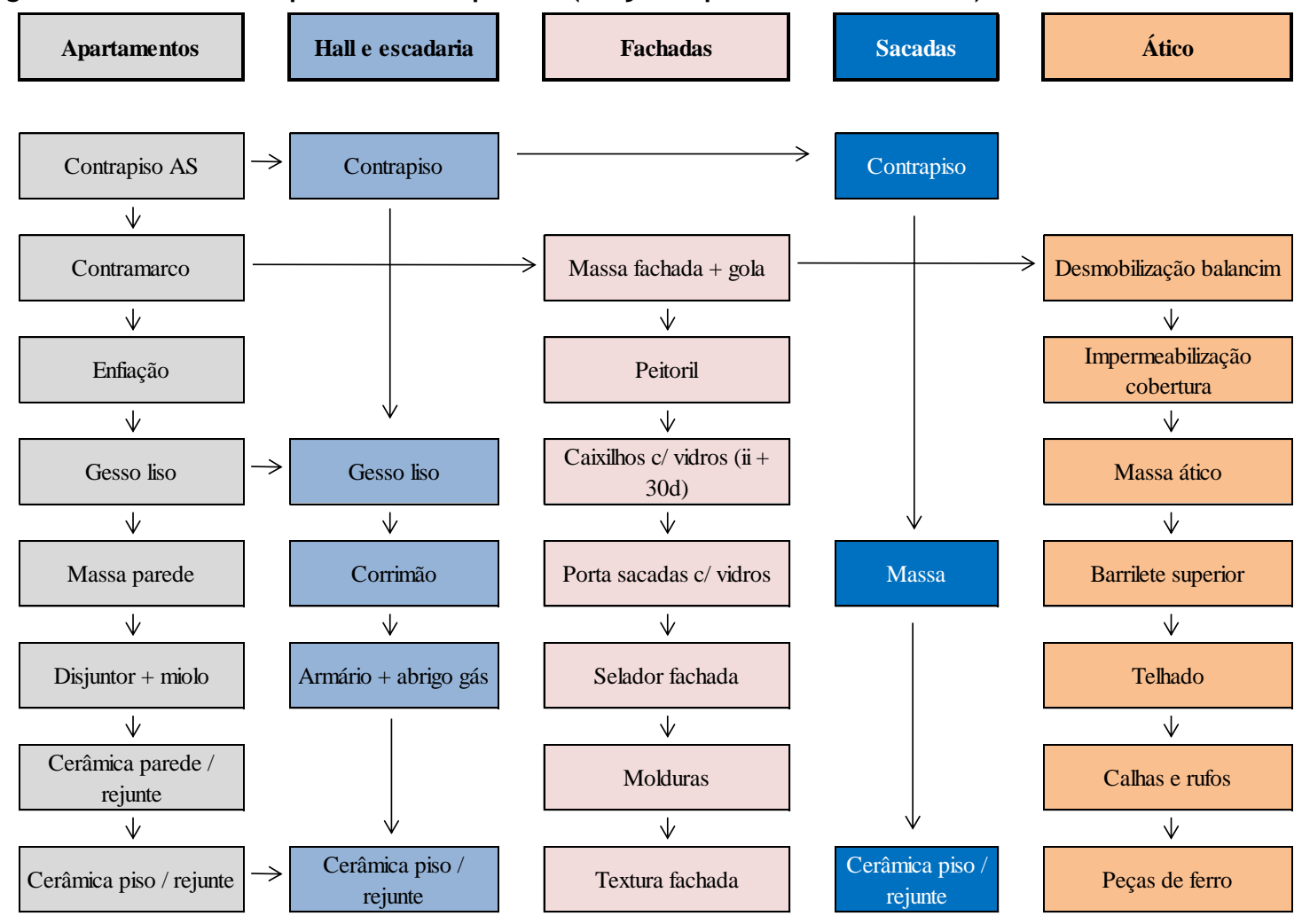

Fonte: Empresa A. 
Com relação à divulgação das informações, a Empresa A adota um modelo de gestão visual nas obras por meio de um quadro, que é a principal forma utilizada pela empresa nas obras. $\mathrm{O}$ quadro fica disponível no canteiro de obras, acessível a todas as equipes. Nele constam os cronogramas mensais e trimestrais (CPM), a curva física, o cronograma de suprimentos, a planilha de metas de produção, a planilha de remoção de restrições, a planilha com a programação semanal e os gráficos de PPC da semana, acumulados e por empreiteiro. Os arquivos do quadro podem ser removidos a qualquer momento para consulta. A Empresa B adota o modelo de relatório de status, que é enviado mensalmente via e-mail para as partes interessadas. Ao final do empreendimento, a empresa divulga um documento em que constam as lições aprendidas durante as fases do empreendimento. A Empresa A não adota o modelo de lições aprendidas.

\section{Proposta de integração dos sistemas}

O método CPM é um pré-requisito para desenvolver o planejamento com base no LBMS, mais especificamente nos conceitos de criticalidade e buffers. A criticalidade é a definição do caminho crítico a partir da identificação de se uma tarefa ou atividade ocasiona o atraso de um empreendimento. Os buffers são definidos como a adição de tempo entre duas atividades, a fim de absorver variações. Buffers são diferentes de folgas, visto que as folgas são identificadas a partir da rede de precedência de atividades, enquanto os buffers são inseridos de forma estratégica (BUCHMANN-SLORUP, 2012).

A incorporação de técnicas CPM na metodologia location-based revelou maior poder da metodologia para o planejamento dos projetos de construção (KENLEY; SEPPANEN, 2010). A folga das atividades é um conceito essencial no método CPM, visto que as atividades com menor folga determinam o caminho crítico do empreendimento. Essa folga é então incorporada no LBMS sob o aspecto de criticalidade. Além disso, as folgas são derivadas das restrições técnicas das atividades, sendo as restrições analisadas no sistema LBMS (BUCHMANNSLORUP, 2012).

O sistema LBMS integra a método do caminho crítico (CPM) no cronograma de fluxo de trabalho. A rede lógica pode ser automaticamente gerada no cronograma CPM, considerando que as tarefas compostas de múltiplos locais estão detalhadas nesse cronograma. Um componente lógico adicional e importante é a explícita manipulação de buffers, em adição às folgas, que são componentes bem conhecidos na lógica do CPM (SEPPANEN et al., 2010). A programação baseada apenas em locais necessita de algoritmo que lhe dê suporte, como o CPM, pois necessita de um relacionamento preciso entre variáveis como durações, sequência construtiva, plano de ataque, restrições e ritmos.

Os sistemas LPS e LBMS são complementares. O LPS foca nos aspectos sociais e de comprometimento do planejamento, enquanto o LBMS é um sistema técnico usado para estruturar as informações e melhorar o processo de planejamento, permitindo a visualização do progresso e a análise de desempenho futuro. Os planejamentos semanais do LPS e os relatórios de médio prazo podem utilizar os dados de progresso e previsão do LBMS como um aviso antecipado para avaliar os efeitos de desvio da produção no empreendimento (SEPPANEN et al., 2010).

Pelo fato de serem complementares, os três sistemas podem trazer uma solução viável ao planejamento e ao controle da produção, visto que um sistema tende a compensar as falhas dos outros. Assim, o planejamento tradicional, adequado para uma visão de longo prazo, porém limitado nas divisões dos locais e análise de restrições, é complementado pelos sistemas LBMS e LPS. Na essência, o LBMS prescreve a definição dos locais de produção, enquanto o LPS analisa e remove as restrições. Assim, o sistema LBMS incorpora transparência e fluxo ao modelo por meio de atividades mais bem definidas e controláveis. Além disso, o LBMS compensa o fato de o LPS não abordar de forma mais ampla as análises de prazos, uma vez que seu foco é o desempenho da produção semanal, e por não considerar que os pacotes mal definidos podem ocasionar atrasos no prazo final do empreendimento.

Modelos integrados de PCP (Planejamento e Controle da Produção) têm sido objeto de estudo de diversos autores brasileiros (FORMOSO et al., 1998; MENDES JUNIOR et al., 1998; MENDES JUNIOR; HEINECK, 1999; SOARES et al., 2002), sendo estes estudos focados principalmente na integração do modelo tradicional com o sistema LPS, abordando, inclusive, a integração do cronograma CPM com a linha de balanço.

Bernardes (2001) desenvolveu um modelo de planejamento e controle da produção para micro e pequenas empresas de construção civil, abordando os princípios de lean construction integrados ao planejamento tradicional, incluindo várias ferramentas e técnicas também consideradas no presente trabalho. A partir disso, os autores desta 
pesquisa propõem um novo modelo que adiciona ferramentas do sistema LBMS aos sistemas LPS e tradicional, sistematizando sua forma de implementação. O modelo integrado proposto não adota a utilização de nenhuma nova ferramenta, aproveitando as ferramentas conhecidas nas empresas. O modelo visa a uma melhor organização e à obtenção de maior sinergia entre os três sistemas, a fim de se atender às necessidades das equipes de produção.

O modelo integrado foi desenvolvido mediante o desenho de um fluxo, considerando a integração horizontal (entre fases) e vertical (dentro de uma mesma fase) dos principais processos dos três sistemas integrados, a partir de uma correlação entre os seguintes itens:

(a) documentos analisados das empresas do estudo de caso;

(b) revisão bibliográfica do PMI (PROJECT..., 2013) referente ao modelo de planejamento tradicional;

(c) revisão bibliográfica de Kenley e Seppanen (2010) referente ao LBMS; e

(d) revisão bibliográfica de Ballard (2000) referente ao LPS.

Com os processos identificados, estes foram organizados conforme as fases do empreendimento, seguindo a classificação do ciclo de vida do PMI (PROJECT..., 2013):
(a) iniciação;
(b) organização e preparação;
(c) execução do trabalho; e
(d) encerramento

Os processos foram numerados de [1] a [32] e classificados sob dois aspectos:

(a) sistema (planejamento tradicional, LBMS ou LPS); e

(b) foco principal (tempo, atividade ou local).

O objetivo de se identificarem os sistemas é facilitar a visualização da integração. O objetivo de se identificar o foco principal é verificar a principal característica de cada processo. A Figura 3 ilustra o fluxo desenvolvido.

Do total de 32 processos propostos, a maioria (18) faz parte da fase de organização e preparação. Devido à quantidade de processos, o tempo disponibilizado para essa fase deve ser suficiente para que o trabalho seja consistente e bem desenvolvido. De acordo com o PMI (PROJECT..., 2013), na fase inicial das obras: (a) o nível de incertezas é mais alto;

(b) os níveis de custo e de pessoal é baixo;

(c) a influência das partes interessadas é alta; e

(d) o custo de mudanças é baixo.

Isso ajuda a compreender quanto o investimento em planejamento na fase inicial pode auxiliar na melhoria de desempenho das obras.

A fase de execução do trabalho possui menos processos que a anterior (12), entretanto ocorre num período maior, pois ocorre durante a construção do empreendimento. Nessa fase, inclusive, ocorre a maior parte dos controles de acompanhamento do planejamento realizado. As fases iniciação e encerramento apresentaram apenas um processo cada, para definição dos prazos e etapas e para lições aprendidas. Isso se deve ao fato de o foco do trabalho estar direcionado principalmente às fases de organização, preparação e execução do trabalho, podendo as demais ser objeto de estudos complementares.

O desempenho das obras pode melhorar devido a alguns fatores importantes no processo de integração:

(a) o planejamento é desenvolvido a partir da definição da ELP, uma das bases do sistema LBMS. O cronograma CPM, o cronograma LBMS e as ferramentas do LPS são desenvolvidos e analisados com base na mesma ELP, facilitando a comunicação das equipes;

(b) o cronograma CPM é utilizado como base para o cronograma LBMS e para o LPS, de forma que as informações constantes nos cronogramas possuam as mesmas bases e datas, atendendo à premissa de que as metas gerenciais estejam em sintonia com as metas de produção;

(c) as necessidades das equipes de produção passam a ser atendidas de forma mais rápida, com melhor qualidade nas informações. As metas passam a ser vinculadas diretamente ao cronograma principal da obra. A confiança da equipe aumenta; e

(d) como as tarefas são detalhadas no nível da ELP, as durações são acompanhadas com maior frequência, identificando-se de forma mais rápida desvios na produção. Além disso, a análise de restrições, o dimensionamento e acompanhamento de equipes de produção e a análise do caminho crítico são acompanhados com maior nível de detalhe, podendo gerar maior assertividade no processo de planejamento do empreendimento. 
Figura 3 - Integração do planejamento tradicional, LBMS e LPS

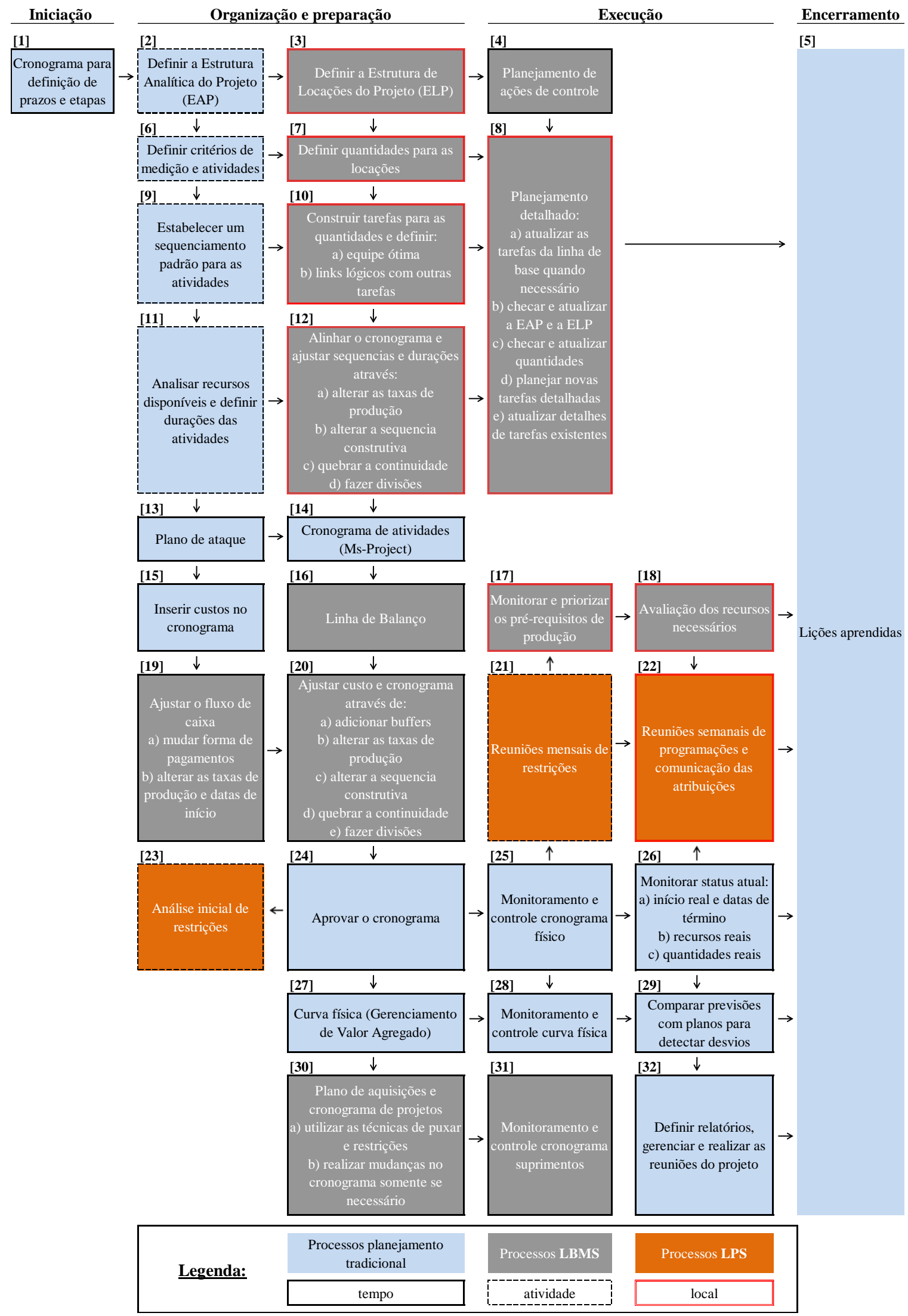

Fonte: adaptado de Kenley e Seppanen (2010). 


\section{Fase iniciação}

O processo de planejamento é iniciado no ciclo de viabilidade com o desenvolvimento de um cronograma para definição de prazos e etapas [1] do empreendimento. Esse material visa definir o prazo total da obra e o período de execução dos principais serviços, considerando uma sequência lógica para os serviços, durações aproximadas e produtividade dos principais recursos envolvidos. O objetivo nesse momento é inserir o prazo no programa de viabilidade do empreendimento e também a distribuição de uma curva física, que servirá de base para a simulação do fluxo de caixa do empreendimento. Como no momento da execução desse cronograma o valor da obra ainda não está definido, a distribuição mensal dos porcentuais de produção é feita com base na participação porcentual de custos a partir de um orçamento de viabilidade. A partir da decisão da empresa em adquirir o terreno para a execução do empreendimento, inicia-se o desenvolvimento da fase de organização e preparação.

\section{Fase organização e preparação}

A partir do cronograma de prazos e etapas [1], inicia-se o desenvolvimento do planejamento na fase de organização e preparação. Usualmente as empresas trabalham com estrutura analítica do projeto (EAPs) padronizadas para o planejamento das obras, possuindo correlação direta com a estrutura de controle de custos. A partir da definição da EAP, define-se também uma divisão menor para os locais, chamada de estrutura de locais do projeto (ELP). A ELP é definida para cada obra, levando-se em consideração a quantidade de torres, de pavimentos e de apartamentos ou salas comerciais, a área de cada uma das unidades e as restrições técnicas de execução, como, por exemplo, separação e divisão das fachadas na prumada em que é instalado o elevador cremalheira. O gerente da obra define a partir daí a melhor estrutura a utilizar. A ELP é fundamental no processo de implantação do sistema LBMS. A Figura 4 ilustra um modelo de integração da EAP [2] com a ELP [3] de parte de um empreendimento.

A partir da definição da EAP e da ELP, estabelecem-se com a equipe da obra os critérios de medição física dos serviços [6] e a sequência construtiva [9] que melhor se adequar ao tipo de empreendimento. Os critérios de medição são voltados ao estabelecimento da forma como o avanço físico da obra será medido, sendo que esses critérios podem ser diferentes dos critérios de medição dos empreiteiros e dos critérios de levantamento de orçamentos. A partir das divisões estabelecidas nos critérios de medição e da estruturação da ELP, são definidas as quantidades a serem alocadas para cada unidade de local da ELP [7].

Figura 4 - Modelo de estrutura parcial de EAP e ELP

\begin{tabular}{|c|c|c|c|c|c|c|c|c|c|c|c|c|c|c|}
\hline & & EAF & & & & & & & ELP & & & & & \\
\hline & & & Ático & Ático & & & & & 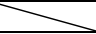 & & & & - & \\
\hline & & & $15^{\circ}$ pavto & salas & hall & escada & sacadas & elevador & fachada 1 & fachada 2 & fachada 3 & fachada 4 & grua & cremalheira \\
\hline & & & $14^{\circ}$ pavto & salas & hall & escada & sacadas & elevador & fachada 1 & fachada 2 & fachada 3 & fachada 4 & grua & cremalheira \\
\hline & & & $13^{\circ}$ pavto & salas & hall & escada & sacadas & elevador & fachada 1 & fachada 2 & fachada 3 & fachada 4 & grua & cremalheira \\
\hline & & & $12^{\circ}$ pavto & salas & hall & escada & sacadas & elevador & fachada 1 & fachada 2 & fachada 3 & fachada 4 & grua & cremalheira \\
\hline & & & $11^{\circ}$ pavto & salas & hall & escada & sacadas & elevador & fachada 1 & fachada 2 & fachada 3 & fachada 4 & grua & cremalheira \\
\hline & & & $10^{\circ}$ pavto & salas & hall & escada & sacadas & elevador & fachada 1 & fachada 2 & fachada 3 & fachada 4 & grua & cremalheira \\
\hline & & & $9^{\circ}$ pavto & salas & hall & escada & sacadas & elevador & fachada 1 & fachada 2 & fachada 3 & fachada 4 & grua & cremalheira \\
\hline & & & $8^{\circ}$ pavto & salas & hall & escada & sacadas & elevador & fachada 1 & fachada 2 & fachada 3 & fachada 4 & grua & cremalheira \\
\hline & & & $7^{\circ}$ pavto & salas & hall & escada & sacadas & elevador & fachada 1 & fachada 2 & fachada 3 & fachada 4 & grua & cremalheira \\
\hline & & & $6^{\circ}$ pavto & salas & hall & escada & sacadas & elevador & fachada 1 & fachada 2 & fachada 3 & fachada 4 & grua & cremalheira \\
\hline$x$ & $\frac{0}{\alpha}$ & & $5^{\circ}$ pavto & salas & hall & escada & sacadas & elevador & fachada 1 & fachada 2 & fachada 3 & fachada 4 & grua & cremalheira \\
\hline & 0 & & $4^{\circ}$ pavto & salas & hall & escada & sacadas & elevador & fachada 1 & fachada 2 & fachada 3 & fachada 4 & grua & cremalheira \\
\hline & & & $3^{\circ}$ pavto & salas & hall & escada & sacadas & elevador & fachada 1 & fachada 2 & fachada 3 & fachada 4 & grua & cremalheira \\
\hline & & & $2^{\circ}$ pavto & salas & hall & escada & sacadas & elevador & fachada 1 & fachada 2 & fachada 3 & fachada 4 & grua & cremalheira \\
\hline & & & $1^{\circ}$ pavto & salas & hall & escada & sacadas & elevador & fachada 1 & fachada 2 & fachada 3 & fachada 4 & grua & cremalheira \\
\hline & & & Térreo & salas & hall & escada & 3 & elevador & fachada 1 & fachada 2 & fachada 3 & fachada 4 & grua & cremalheira \\
\hline & & & $4 .^{\circ}$ sobresolo & Trecho 1 & hall & escada & Trecho 2 & elevador & fachada 1 & fachada 2 & fachada 3 & fachada 4 & grua & cremalheira \\
\hline & & & $3 .^{\circ}$ sobresolo & Trecho 1 & hall & escada & Trecho 2 & elevador & fachada 1 & fachada 2 & fachada 3 & fachada 4 & grua & cremalheira \\
\hline & & $\bar{\Xi}$ & 2. ${ }^{\circ}$ sobresolo & Trecho 1 & hall & escada & Trecho 2 & elevador & fachada 1 & fachada 2 & fachada 3 & fachada 4 & grua & cremalheira \\
\hline & & $\bar{J}$ & 1. ${ }^{\circ}$ sobresolo & Trecho 1 & hall & escada & Trecho 2 & elevador & fachada 1 & fachada 2 & fachada 3 & fachada 4 & grua & cremalheira \\
\hline & & $=$ & $1 .^{\circ}$ subsolo & Trecho 1 & hall & escada & Trecho 2 & elevador & & & & & grua & cremalheira \\
\hline & & & Fundações & Trecho 1 & Trecho 2 & Trecho 3 & Trecho 4 & & $x$ & & & 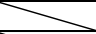 & & \\
\hline & & & Contenções & Lateral 1 & Lateral 2 & Lateral3 & Lateral 4 & & & & & & & \\
\hline & & & [ERNA & Lojas & Teatro & Trecho 1 & Trecho 2 & Trecho 3 & Trecho 4 & Trecho 5 & Trecho 6 & Trecho 7 & Trecho 8 & Trecho 9 \\
\hline
\end{tabular}

276 Olivieri, H.; Granja, A. D.; Picchi, F. A. 
Com o sequenciamento padrão e as quantidades dos locais definidas, são construídas as tarefas para as quantidades [10], levando-se em consideração as equipes e os vínculos lógicos com outras atividades. De acordo com as quantidades, as tarefas podem ser agrupadas ou desmembradas. Com o sequenciamento padrão estabelecido é possível analisar os recursos disponíveis e, com base nesta análise, definir também as durações das atividades [11]. Na prática, a análise dos recursos e a definição das durações das atividades são realizadas de forma simultânea, visto que em alguns casos os recursos disponíveis limitam as durações, e em outros casos as durações são impostas e os recursos dimensionados para atendêlas.

Definidas tarefas, vínculos, recursos e durações, é possível o alinhamento do cronograma e ajustes das sequências e durações das tarefas [12], por meio da alteração das taxas de produção e sequência construtiva, quebra de continuidade entre serviços e divisões para as tarefas com durações muito longas.

A definição do plano de ataque da obra [13] ocorre a partir de:

(a) análise do caminho crítico;

(b) premissas contratuais de faseamento (por exemplo, três torres com datas de entrega diferentes);

(c) restrições de sequenciamento sugerido para as contenções e fundações;

(d) considerações e restrições da logística;

(e) recursos disponíveis e durações das atividades;

(f) condições meteorológicas previstas para cada fase da obra (contenções, fundações, estrutura, fachadas e impermeabilizações); e

(g) condições de segurança do trabalho para cada situação.

Alinhado o cronograma e definido o plano de ataque, é possível estabelecer o cronograma de atividades executivo da obra [14], além da inserção de custos nas atividades do cronograma [15]. Analisam-se as datas das atividades, o caminho crítico do empreendimento, os períodos em que cada atividade está ocorrendo e a sobreposição ou folga de recursos. Em paralelo ao cronograma de atividades, desenvolve-se uma linha de balanço [16], a fim de melhor visualização da sequência construtiva, do caminho crítico, das eventuais folgas existentes e do prazo total do empreendimento.
Com os custos inseridos no cronograma podem-se alterar as formas de pagamento, alterar as taxas de produção e datas de início e término dos serviços, obtendo-se o ajuste do fluxo de caixa do empreendimento [19]. Após o fluxo de caixa definido $\mathrm{e}$ as análises críticas realizadas no cronograma de atividades e na linha de balanço, os cronogramas são ajustados por meio da adição de buffers, alteração das taxas de produção, alteração de sequências construtivas, quebra de continuidade e novas divisões em atividades. Como produto desse processo, obtêm-se ajustes nos custos e cronograma do empreendimento [20]. O cronograma executivo é então aprovado de forma definitiva [24], definindo-se a linha de base do planejamento.

Utilizando-se as técnicas propostas no sistema LPS, uma análise inicial de restrições [23] é realizada após a aprovação do cronograma, a fim de se identificarem as principais restrições inerentes ao início da obra. São consideradas restrições às ações (ou falta de ações) que podem impactar no início ou execução de determinado serviço na obra.

A partir do estabelecimento do cronograma executivo, pode-se utilizar a técnica de AVA para a geração de uma curva física [27], que leva em consideração a distribuição das atividades e os respectivos pesos atribuídos a cada uma delas. Autores como Barcaui et al. (2006) destacam a importância da aplicação da AVA no gerenciamento de projetos como forma de medir as obras e obter índices de desempenho e perspectivas futuras.

Definidos o cronograma executivo e a curva física, ocorre o desenvolvimento do plano de aquisições [30] ou cronograma de suprimentos, que tem por objetivo auxiliar a equipe de obra nas contratações dos principais insumos e projetos. Esse cronograma leva em consideração:

(a) o tempo de contratação requerido pela empresa contratante em cada item;

(b) as restrições de fornecimento;

(c) os prazos estipulados pelos fornecedores para entrega de materiais ou mobilização; e

(d) os eventuais acordos de compra já definidos pelas empresas.

\section{Fase execução do trabalho}

$\mathrm{O}$ primeiro plano a se desenvolver, anterior ao início das obras, é um planejamento de ações de controle [4], visando estabelecer uma sistemática para o acompanhamento do empreendimento. Com o início das obras e a partir do material elaborado 
na fase de organização e preparação, inicia-se a fase de execução do trabalho e também dos controles. Ações como alterações de algumas tarefas de linha de base, atualização de EAP e ELP, atualização de quantidades, inserção de novas tarefas e atualização de tarefas existentes fazem parte do planejamento detalhado [8], e essas alterações devem ser validadas pelo gestor da obra e atualizadas no material de planejamento gerado.

O cronograma físico é atualizado e monitorado periodicamente [25], usualmente de forma mensal. As atividades realizadas são apuradas em campo e lançadas no cronograma, considerando-se o início e o término real, além de recursos alocados e quantidades reais praticadas [26]. Antecipações e atrasos devem ser discutidos com o gestor da obra, a fim de exercer atividades de controle, restabelecendo o plano inicial. A partir do cronograma atualizado, é gerada a curva física atualizada [28]. Com esses dois cronogramas é possível avaliar o progresso da obra, assim como o comparativo com a linha de base estabelecida. No cronograma físico é possível verificar os prazos, e na curva física verifica-se o progresso porcentual das atividades e do empreendimento, correlacionando essas informações com a curva de desembolso.

Com base nas informações geradas pela atualização do cronograma físico e da curva física, são comparadas as previsões com os planos iniciais [29], a fim de se detectarem eventuais desvios. A partir das análises, são gerados relatórios específicos e também realizadas as reuniões periódicas do empreendimento [32], com a participação das equipes gerenciais, de planejamento e de produção. A integração dos três sistemas de planejamento auxilia no relatório e nas reuniões, visto que a equipe gerencial analisa de forma prioritária os itens do planejamento tradicional (CPM, suprimentos e curva física), enquanto a equipe de produção possui maior foco na linha de balanço (LBMS) e na análise de restrições e programação semanal, itens do LPS.

O cronograma de suprimentos é atualizado e controlado mensalmente [31], levando-se em consideração as datas previstas e realizadas dos principais insumos, possibilitando um acompanhamento dos resultados. Outra informação disponibilizada nesse cronograma é o porcentual das contratações. A atualização do cronograma é importante para a realização das reuniões de análise restrições.

Reuniões mensais de restrições [21], também conhecidas como planejamento de médio prazo (PMP), são realizadas em conjunto com a atualização dos cronogramas. O objetivo é analisar as atividades que ocorrerão num prazo de 90 dias, listando as eventuais restrições que podem alterar o desempenho planejado. O PMP é o elo entre o cronograma de atividades e o planejamento semanal (planejamento de curto prazo). Além da lista de restrições, é definido um plano de ação para a recuperação das atividades em atraso. Semanalmente as restrições devem ser acompanhadas pela equipe da obra, a fim de acompanhar o andamento planejado e evitar imprevistos tardiamente identificados.

A partir das reuniões de restrições, os prérequisitos de produção [17] são monitorados e priorizados, avaliando-se dessa forma os recursos necessários para a execução das atividades [18]. Os pré-requisitos de produção são entendidos como as tarefas a realizar na programação semanal. Além das restrições removidas, devem ser considerados itens como logística, recursos necessários (materiais, mão de obra e equipamentos) e restrições técnicas.

As reuniões semanais de produção [22] são baseadas na produção mensal estabelecida no cronograma de atividades, na ELP, nas reuniões de restrições e na análise dos recursos disponíveis. Essas reuniões também são conhecidas como planejamento de curto prazo (PCP). Conforme demonstrado na Figura 5, o planejamento de curto prazo pode dividir as atividades por local (seguindo a ELP), por equipe e por dia da semana, possibilitando a identificação e o tratamento das causas de não cumprimento das atividades.

\section{Fase encerramento}

O principal documento gerado na fase de encerramento é o Relatório de Lições Aprendidas [5]. Muitas vezes caracterizado como desnecessário, esse documento permite o registro histórico de fatores positivos e negativos ocorridos durante a obra, possibilitando que erros sejam evitados no futuro e que boas práticas implantadas possam ser utilizadas em outras obras. O recomendado é que esse documento seja preenchido ao longo da obra, e não somente após sua conclusão, fazendo com que informações importantes sejam esquecidas. Esse processo foi identificado na Figura 3 como um item do planejamento baseado em atividades por ser parte integrante do modelo tradicional. Não ocorreu a identificação quanto ao foco principal, pois se entende que esse processo esteja ligado e dependa diretamente dos fatores ocorridos antes e durante $\mathrm{o}$ empreendimento. 
Figura 5 - Planejamento de curto prazo

\begin{tabular}{|c|c|c|c|c|c|c|c|c|c|c|c|c|c|c|c|c|c|c|}
\hline \multirow{3}{*}{ Item } & \multirow{3}{*}{ Pacote de trabalho } & \multicolumn{3}{|c|}{ Local } & \multirow{3}{*}{\multicolumn{2}{|c|}{ Equipe }} & \multicolumn{2}{|c|}{ Responsável } & \multirow{3}{*}{ Status } & \multicolumn{7}{|c|}{ Dias da semana } & \multirow{3}{*}{$\begin{array}{c}\% \\
\text { Realizado }\end{array}$} & \multirow{3}{*}{$\begin{array}{l}\text { Causas } \\
\text { atraso / } \\
\text { sucesso }\end{array}$} \\
\hline & & \multirow{2}{*}{ Torre } & \multirow{2}{*}{ Pavto } & \multirow{2}{*}{ Unidade } & & & \multirow{2}{*}{ Empresa } & \multirow{2}{*}{ Mestre } & & 9 & 10 & 11 & 12 & 13 & 14 & 15 & & \\
\hline & & & & & & & & & & $\mathbf{S}$ & $\mathbf{T}$ & $\mathbf{Q}$ & $\mathbf{Q}$ & $\mathbf{S}$ & $\mathbf{S}$ & D & & \\
\hline \multirow{2}{*}{1} & \multirow{2}{*}{ Grauteamento das alvenarias } & \multirow{2}{*}{ A } & \multirow{2}{*}{3} & \multirow{2}{*}{31 e 32} & Oficial & 1 & \multirow{2}{*}{ A } & \multirow{2}{*}{ Arthur } & Prev. & & & & & & & & \multirow{2}{*}{$100,00 \%$} & \multirow{2}{*}{ Sucesso } \\
\hline & & & & & Ajud & 1 & & & Real & & & & & & & & & \\
\hline \multirow{2}{*}{2} & \multirow{2}{*}{$\begin{array}{l}\text { Colocação da escada pré- } \\
\text { moldada }\end{array}$} & \multirow{2}{*}{$\mathrm{A}$} & \multirow{2}{*}{3} & & Oficial & & \multirow{2}{*}{ A } & \multirow{2}{*}{ Arthur } & Prev. & & & & & & & & $10000 \%$ & Sucesso \\
\hline & & & & & Ajud & 1 & & & Real & & & & & & & & $100,00 \%$ & Sucesso \\
\hline & Montagem do escoramento da & & Locaçã & das & Oficial & & & João & Prev. & & & & & & tifica & & & \\
\hline 3 & laje & A & & & \begin{tabular}{|l} 
Ajud \\
\end{tabular} & 2 & B & Paulo & Real & & & & & & sual d & & $100,00 \%$ & Sucesso \\
\hline & Montagem de laje pré- & & & & Oficial & 1 & 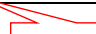 & ปمล̃ก & Prev. & & & & & & al de & & & \\
\hline 4 & moldada & A & 3 & - & Ajud & 1 & Dimens & ionar & Real & & & & & & & & $100,00<$ & Sucesso \\
\hline 5 & $\varnothing>$ & $A$ & 3 & 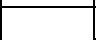 & Oficial & 1 & recur & nara & Prev. & & & & & & & & & uração \\
\hline 5 & N Descrição clara do le & A & 3 & - & Ajud & 1 & $\begin{array}{l}\text { humano } \\
\text { as tar }\end{array}$ & $\begin{array}{l}\text { para } \\
\text { fas }\end{array}$ & Real & & & & & & & & 100, & 003 \\
\hline 6 & I. trabalho a realizar - & $A$ & 3 & 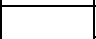 & Oficial & 1 & as tant & Márcio & Prev. & & & & & & & & & iltados de \\
\hline 6 & h linguagem deve estar & A & 3 & - & Ajud & 1 & D & Marcio & Real & & & & & & & & $90,00 \%$ & material \\
\hline & técnica e ser & & 3 & & Oficial & 2 & $\mathrm{C}$ & Paulo & Prev. & & & & & & & & & \\
\hline 7 & compreendida pela & A & 3 & - & Ajud & 2 & $\mathrm{C}$ & Paulo & Real & & & & & & & & $70,00 \%$ & Predecessora \\
\hline 8 & equipe de campo que & A & 4 & 41 e 42 & Oficial & 2 & A & Arthur & Prev. & & & & & & & & $50.00 \%$ & Predecessora \\
\hline 8 & & A & 4 & $41 \mathrm{e} 42$ & Ajud & 2 & A & Arthur & Real & & & & & & & & $50,00 \%$ & Predecessora \\
\hline 9 & Montagem da proteção & A & 8 & fachadas & Oficial & & A & Arthur & Prev. & & & & & & & & $5000 \%$ & Chuva \\
\hline & periférica & A & & 1 e 2 & Ajud & 2 & A & & Real & & & & & & & & & \\
\hline
\end{tabular}

\section{Avaliação-piloto do modelo integrado}

Como forma de avaliar a viabilidade do modelo de planejamento integrado com profissionais da indústria de construção, realizou-se uma avaliação piloto por meio de entrevistas com uma série de questões estruturadas. Os principais objetivos da avaliação piloto foram:

(a) identificação do que precisa ser melhorado no modelo atual de planejamento que utilizam;

(b) como o planejamento integrado poderia contribuir com essas melhorias;

(c) a viabilidade de integração de três sistemas distintos, porém complementares;

(d) a melhoria que a integração poderia proporcionar no cumprimento dos prazos e metas; e

(e) os benefícios, dificuldades de implantação e possíveis lacunas do modelo integrado.

O Quadro 4 apresenta uma síntese com relação aos resultados da avaliação piloto do modelo integrado, considerando apenas questões vinculadas à concepção do modelo integrado, sendo as demais questões utilizadas para apontar o estágio atual de gestão nas obras em que atuam os profissionais entrevistados.

De maneira geral, boa parte dos entrevistados considerou possível integrar os três sistemas de planejamento propostos num modelo integrado, contribuindo para soluções de melhorias identificadas no modelo atual de gestão que utilizam, além de considerarem viável a utilização desse modelo em suas próprias obras. Como lacunas e principais limitações identificadas para a implementação do modelo, os entrevistados destacaram os seguintes itens:
(a) pessoas;
(b) necessidade de treinamentos frequentes;
(c) qualificação dos profissionais; e
(d) barreiras culturais.

\section{Conclusões}

O modelo integrado sistematiza a integração de três sistemas de planejamento distintos, porém complementares, quais sejam: planejamento tradicional (CPM), LBMS e LPS. De uma forma geral, as empresas construtoras já estão aculturadas em suas rotinas com o planejamento tradicional. Uma vez que o modelo proposto mantém elementos do planejamento tradicional em sua essência, sua assimilação poderá ser facilitada por empresas do setor.

modelo proposto mantêm a possibilidade de controle real de tempos e custos. Por sua vez, os elementos do LPS contidos na proposta direcionam o tratamento da variabilidade $\mathrm{e}$ as incertezas características dos empreendimentos do setor. Por fim, o LBMS tem como principal função a implantação do fluxo de trabalho de maneira transparente. Portanto, vislumbra-se que o modelo integrado proposto possa compensar as deficiências de sistemas de planejamento e controle da produção que utilizam os métodos de maneira isolada, enaltecendo-se a complementaridade e a sinergia entre eles. 


\section{Quadro 4 - Avaliação-piloto do modelo integrado}

\begin{tabular}{|c|c|}
\hline Questões & Respostas \\
\hline $\begin{array}{l}\text { Você acha possível integrar três sistemas distintos, e de } \\
\text { certa forma antagônicos? }\end{array}$ & $\begin{array}{l}\text { Definitivamente sim: } 17,9 \% \text {; Provavelmente sim: } \\
\text { 79,5\%; Provavelmente não: } 2,6 \%\end{array}$ \\
\hline $\begin{array}{l}\text { Em sua opinião, o modelo de planejamento integrado } \\
\text { poderia contribuir com as melhorias identificadas no seu } \\
\text { modelo de planejamento atual? }\end{array}$ & Sim: 100,0\%; Não: $0 \%$. \\
\hline $\begin{array}{l}\text { Você consideraria utilizar o modelo integrado em suas } \\
\text { obras? }\end{array}$ & Sim: 94,9\%; Não: 5,1\%. \\
\hline $\begin{array}{l}\text { Onde você entende que ocorreriam os maiores benefícios } \\
\text { com a adoção de um modelo integrado? }\end{array}$ & $\begin{array}{l}\text { Qualidade das informações: } 84,6 \% \text {; Integração } \\
\text { entre níveis de planejamento: } 74,4 \% \text {; Gestão de } \\
\text { recursos: } 66,7 \% \text {. }\end{array}$ \\
\hline $\begin{array}{l}\text { Quais seriam os pontos falhos para a implementação } \\
\text { deste modelo? }\end{array}$ & $\begin{array}{l}\text { Pessoas: } 76,9 \% ; \text { Necessidade de treinamentos } \\
\text { frequentes: } 51,3 \% .\end{array}$ \\
\hline $\begin{array}{l}\text { Quais seriam as principais limitações para a } \\
\text { implementação deste modelo? }\end{array}$ & $\begin{array}{l}\text { Qualificação dos profissionais: } 74,4 \% \text {; Barreiras } \\
\text { culturais: } 56,4 \% \text {; Equipe de produção: } 53,8 \% \text {. }\end{array}$ \\
\hline $\begin{array}{l}\text { A implantação deste modelo poderia melhorar o processo } \\
\text { de tomada de decisões? }\end{array}$ & Concordo totalmente: $30,8 \%$; Concordo: $69,2 \%$ \\
\hline $\begin{array}{l}\text { Com este modelo, as metas gerenciais e metas de } \\
\text { produção estariam alinhadas, facilitando a comunicação e } \\
\text { o estabelecimento de objetivos comuns }\end{array}$ & Concordo totalmente: $23,1 \%$; Concordo: $76,9 \%$. \\
\hline $\begin{array}{l}\text { O modelo integrado pode tornar o sistema de } \\
\text { planejamento mais estável e sistematizado, evitando } \\
\text { surpresas futuras em relação ao cumprimento das metas }\end{array}$ & $\begin{array}{l}\text { Concordo totalmente: } 17,9 \% \text {; Concordo: } 76,9 \% \text {; } \\
\text { Discordo: } 5,2 \% \text {. }\end{array}$ \\
\hline
\end{tabular}

Os elementos do planejamento tradicional do Os resultados obtidos por meio da avaliação piloto com profissionais de planejamento e gestão de obras nas empresas pesquisadas sugerem que a integração dos três sistemas propostos é viável. Essa integração poderá contribuir com melhorias na análise do caminho crítico, na melhor preparação das equipes para o início das atividades, num dimensionamento dos recursos mais efetivo e no estabelecimento de um fluxo de trabalho contínuo para as atividades. Além disso, o modelo integrado poderia aprimorar a assertividade no cumprimento dos prazos e metas estabelecidas na linha de base do planejamento, melhorar o processo de tomada de decisões e facilitar a comunicação e o estabelecimento de objetivos comuns em todos os níveis hierárquicos. Os resultados da avaliação piloto também permitem o entendimento de que o modelo integrado poderia tornar o sistema de planejamento mais estável, sistematizado e aderente ao cumprimento das metas.

Como pontos de atenção na implantação do modelo integrado, os resultados da avaliação piloto sugerem que quatro fatores principais devem ser levados em consideração:

(a) pessoas; (b) necessidade de treinamentos frequentes;

(c) qualificação dos profissionais; e

(d) barreiras culturais.

$\mathrm{O}$ fator pessoas refere-se principalmente à gestão e a aspectos comportamentais, que necessitam ser observados e ajustados ao longo do processo de adoção do modelo. Caracteriza-se por ser um ponto-chave para seu sucesso. $\mathrm{O}$ fator necessidade de treinamentos frequentes refere-se ao cuidado constante na capacitação das equipes e monitoramento da eficácia e eficiência dos treinamentos. A qualificação dos profissionais possui ligação direta com os treinamentos frequentes, porém se deve avaliar o grau e a maturidade gerencial dos profissionais envolvidos. Com relação às barreiras culturais, o modelo precisa exigir poucas alterações na cultura e rotinas atuais das equipes para obter maior comprometimento por parte dos profissionais envolvidos.

Finalmente, o modelo necessita ser testado na prática, e, dessa forma, sugerem-se como pesquisas futuras a aplicação do modelo em casos reais e abordagens críticas sobre o LBMS, tendo em vista a escassez de publicações científicas nessa temática. 


\section{Referências}

ASSUMPÇÃO, J. F. P. Gerenciamento de Empreendimentos na Construção Civil: modelo para planejamento estratégico da produção de edifícios. São Paulo, 1996. Tese (Doutorado em Engenharia Civil) - Escola de Engenharia, Universidade de São Paulo, São Paulo, 1996.

ASSUMPÇÃO, J. F. P.; FUGAZZA, A. E. C. Uso de Redes de Precedência Para Planejamento da Produção em Edifícios. In: ENCONTRO

NACIONAL DE TECNOLOGIA DO AMABIENTE CONSTRUÍDO, 7., Florianópolis, 1998. Anais... Florianópolis: UFSC, ANTAC, 1998.

BALLARD, H. G. The Last Planner System of Production Control. Birmingham, 2000. 192 f. Thesis (Doctor of Philosophy) - School of Civil Engineering, University of Birmingham, Birmingham, 2000.

BALLARD, H. G.; HOWELL, A. Competing Construction Management Paradigms. Lean Construction Journal, v. 1, n. 1, p. 38-45, 2004.

BARCAUI, A. et al. Gerenciamento do Tempo em Projetos. Rio de Janeiro: Editora FGV, 2006.

BERNARDES, M. M. S. Desenvolvimento de Um Modelo de Planejamento e Controle da Produção Para Micro e Pequenas Empresas de Construção. Porto Alegre, 2001. Tese (Doutorado em Engenharia Civil) - Escola de Engenharia, Universidade Federal do Rio Grande do Sul, Porto Alegre, 2001.

BORTOLAZZA, R. C.; FORMOSO, C. T. A Quantitative Analysis of Data Collected From the Last Planner System in Brazil. In: ANNUAL CONFERENCE OF THE INTERNATIONAL GROUP FOR LEAN CONSTRUCTION, 14., Santiago, 2006. Proceedings... Santiago, 2006.

BUCHMANN-SLORUP, R. Criticality in Location-Based Management of Construction. Denmark, 2012. 202 f. Thesis (Ph.D. ) Department of Management Engineering, Technical University of Denmark, Denmark, 2012.

BULHOES, I. R.; PICCHI, F.A. Redução do Tamanho do Lote em Projetos Como Estratégia de Implementação do Fluxo Contínuo em Sistemas Pré-Fabricados. Ambiente Construído, Porto Alegre, v. 13, n. 3, p. 161-175, jul./set. 2013. CARDIM, R. F.; GRANJA, A. D. Proposta de PCP Com Base no Método da Corrente Crítica e do Last Planner System. In: SIMPÓSIO BRASILEIRO DE GESTÃO E ECONOMIA DA CONSTRUÇÃO, 7., João Pessoa, 2011. Anais... João Pessoa, 2011.
FORMOSO, C. T. et al. Developing a Model for Planning and Controlling Production in Small Sized Building Firms. In: ANNUAL CONFERENCE OF THE INTERNATIONAL GROUP FOR LEAN CONSTRUCTION, 6., Guarujá, 1998. Proceedings... Guarujá, 1998.

HAMZEH, F. et al. Rethinking Lookahead Planning to Optimize Construction Workflow. Lean Construction Journal, v. 1, n. 1, p. 15-34, 2012.

HEINECK, L. F. M. Curvas de Agregação de Recursos no Planejamento e Controle da Edificação: aplicações a obras e a programas de construção. Porto Alegre: Caderno de Engenharia, 1990.

HUBER, B.; REISER, P. The Marriage of CPM and Lean Construction. In: ANNUAL CONFERENCE OF THE INTERNATIONAL GROUP FOR LEAN CONSTRUCTION, 11., Blacksburg, 2003. Proceedings... Blacksburg, 2003.

JONGELING, R.; OLOFSSON, T. A Method for Planning of Work-Flow by Combined Use of Location-Based Scheduling and 4D CAD.

Automation in Construction, v. 16, n. 2, p. 189198, 2007.

KEMMER, S. L. et al. Using the Line of Balance For Production System Design. In: ANNUAL CONFERENCE OF THE INTERNATIONAL GROUP FOR LEAN CONSTRUCTION, 16., Manchester, 2008. Proceedings... Manchester, 2008.

KENLEY, R. Project Micromanagement: practical site planning and management of work flow. In: ANNUAL CONFERENCE OF THE INTERNATIONAL GROUP FOR LEAN CONSTRUCTION, 12., Copenhagen, 2004. Proceedings... Copenhagen, 2004.

KENLEY, R.; SEPPANEN, O. Location-Based Management for Construction: planning, scheduling and control. Abingdon: Spon, 2010.

KIM, Y. W.; BALLARD, G. Management Thinking in the Earned Value Method System and the Last Planner System. Journal of Management in Engineering, v. 26, n. 4, p. 223-228, 2010.

KOSKELA, L. J. et al. The Foundations of Lean Construction. In: BEST, R.; DE VALENCE, G. (Eds.). Design and Construction: building in value. Oxford, UK: Butterworth Heinemann, 2002. 
KOSKELA, L. J. et al. Last Planner and Critical Chain in Construction Management: comparative analysis, In: ANNUAL CONFERENCE OF THE INTERNATIONAL GROUP FOR LEAN

CONSTRUCTION, 18., Haifa, 2010.

Proceedings... Haifa, 2010.

KOSKELA, L. et al. If CPM Is So Bad, Why Have We Been Using it So Long? In: ANNUAL CONFERENCE OF THE INTERNATIONAL GROUP FOR LEAN CONSTRUCTION, 22., Oslo, 2014. Proceedings... Oslo, 2014.

LAKATOS, E. M.; MARCONI, M. A. Técnicas de Pesquisa. 3. ed. São Paulo: Atlas, 1996.

LAUFER, A.; TUCKER, R. L. Is Construction Management Really Doing Its Job? Construction Management and Economics, v. 5, p. 243-266, 1987.

LOWE, R. H. et al. A Comparison of LocationBased Scheduling With the Traditional Critical Path Method. In: ANNUAL MEETING AMERICAN COLLEGE OF CONSTRUCTION LAWYERS, San Francisco, 2012. Proceedings... San Francisco, 2012.

LUCKO, G. et al. Challenges and Opportunities For Productivity Improvement Studies in Linear, Repetitive, and Location-Based Scheduling. Construction Management and Economics, v. 32, n. 6, p. 575-594, 2013.

MENDES JR., R. et al. Preplanning Method For Multi-Story Building Construction Using Line of Balance. In: ANNUAL CONFERENCE OF THE INTERNATIONAL GROUP FOR LEAN CONSTRUCTION, 6., Guarujá, 1998. Proceedings... Guarujá, 1998.

MENDES JUNIOR, R.; HEINECK, L. F. M. Towards Production Control on Multi-Story Building Construction Sites. In: ANNUAL CONFERENCE OF THE INTERNATIONAL GROUP FOR LEAN CONSTRUCTION, 7., Berkeley, 1999. Proceedings... Berkeley, 1999.

O EMPREITEIRO. Ranking da Engenharia Brasileira. São Paulo, ed. N. 510, jul. 2012. Disponível em: <http://www.oempreiteiro.com.br/Edicoes/124/Jul ho_2012_.aspx>. Acesso em: 12 fev. 2015.
PROJECT MANAGEMENT INSTITUTE. A Guide to the Project Management Body of Knowledge. $5^{\text {th }}$. ed. New York: PMI, 2013.

SEPPANEN, O. et al. The Combination of Last Planner System and Location-Based Management System. Lean Construction Journal, v. 1, n. 1, p. 43-54, 2010.

SEPPANEN, O. et al. Effects of the LocationBased Management System on Production Rates and Productivity. Construction Management and Economics, v. 32, n. 6, p. 608-624, 2014.

SOARES, A. C. et al. Improving the Production Planning and Control System in a Building Company: contributions after stabilization. In: ANNUAL CONFERENCE OF THE INTERNATIONAL GROUP FOR LEAN CONSTRUCTION, 10., Gramado, 2002. Proceedings... Gramado, 2002.

TANMAYA, K. et al. Production Control Using Location-Based Management System on a Hospital Construction Project. In: ANNUAL CONFERENCE OF THE INTERNATIONAL GROUP FOR LEAN CONSTRUCTION, 20., San Diego, 2012. Proceedings... San Diego, 2012.

VIANA, D. D. et al. A Survey on the Last Planner System: impacts and difficulties for implementation in Brazilian companies. In: ANNUAL CONFERENCE OF THE INTERNATIONAL GROUP FOR LEAN CONSTRUCTION, 18., Haifa, 2010. Proceedings... Haifa, 2010.

VIANA, D. D. et al. Guidelines for Integrated Planning and Control of Engineer-to-Order Prefabrication Systems. In: ANNUAL CONFERENCE OF THE INTERNATIONAL GROUP FOR LEAN CONSTRUCTION, 21., Fortaleza, 2013. Proceedings... Fortaleza, 2013.

WHETTEN, D. A. What Constitutes a Theoretical Contribution? The Academy of Management Review, v. 14, n. 4, p. 490-495, 1989.

YIN, R. K. Estudo de Caso: planejamento e métodos. Porto Alegre: Bookman, 2010. 


\section{Hylton Olivieri}

Laboratório de Gerenciamento na Construção, Departamento de Arquitetura e Construção | Universidade Estadual de Campinas | Odebrecht Realizações | Rua Lemos Monteiro, 120, $19^{\circ}$ andar, Butantã | São Paulo - SP - Brasil | CEP 05501-050 | Tel.: (11) 3554-8455 E-mail: hylton.olivieri@gmail.com

\section{Ariovaldo Denis Granja}

Laboratório de Gerenciamento na Construção, Departamento de Arquitetura e Construção | Universidade Estadual de Campinas | Av. Albert Einstein, 951, Cidade Universitária Zeferino Vaz, Barão Geraldo | Campinas - SP - Brasil | Caixa Postal 6021 | CEP $13083-852$ | Tel.: (19) 3521-2082 | E-mail: adgranja@fec.unicamp.br

\section{Flávio Augusto Picchi}

Laboratório de Gerenciamento na Construção, Departamento de Arquitetura e Construcão | Universidade Estadual de Campinas | Lean Institute Brasil | R. Brás Cubas, 187, Aclimação | São Paulo - SP - Brasil | CEP 04105-063 | Tel.: (11) 5571-0804 |

E-mail: fpicchi@lean.org.br

\section{Revista Ambiente Construído}

Associação Nacional de Tecnologia do Ambiente Construído

Av. Osvaldo Aranha, $99-3^{\circ}$ andar, Centro

Porto Alegre - RS - Brasil

$$
\text { CEP } 90035-190
$$

Telefone: +55 (51) 3308-4084

Fax: +55 (51) 3308-4054

www.seer.ufrgs.br/ambienteconstruido

E-mail: ambienteconstruido@ufrgs.br 